\title{
Facebook's Digital Currency Venture "Diem": the new Frontier ... or a Galaxy far, far away?
}

\author{
Jahja Rrustemi and Nils S. Tuchschmid
}

\author{
I There will be an electronic currency, and it will be universal, and we must \\ accept that fact. "' \\ John McAfee
}

\begin{abstract}
This article focuses on Facebook's new digital currency, initially called "Libra" and renamed in December 2020 "Diem", that has been designed and proposed by the Diem Association (formerly the Libra Association). It briefly reflects on the historical meaning of money and currency, as well as "local currencies" viewed as precursors to the new "digital currencies" or "cryptocurrencies". The paper presents a general overview of the Diem project, particularly from the perspective of financial theory and practise. It looks specifically into Diem's business model and analyzes the project's planned and potential revenue streams, according to official documents published by the Diem Association. The research identifies potential obstacles and hurdles this digital currency would (since it has not happened yet) face on launch day and assesses whether the project is feasible in its current form. In the authors' view, although some early concerns were addressed in the Diem White Paper 2.0, the Diem project is only questionably ready for commercial launch in its current state. Speaking directly to the financial aspects of the Diem Association's project, the current regulatory hurdles and institutional pressures seem difficult to bypass without making some additional noticeable and meaningful changes to Diem.
\end{abstract}

\section{Introduction}

Thanks to technological advances, new forms of electronic currency are now possible and already available. In particular, distributed ledger-based digital "blockchain" technology now offers a secure transaction-oriented system free from censorship and control by central government powers. This technology, invented by a pseudonymous figure (or team) "Satoshi Nakamoto", has allowed so-called "cryptocurrencies", such as Bitcoin, Ethereum and Ripple, to create a new digital economy. Due to their "decentralized" character, these cryptocurrencies are poised to potentially disrupt national and central bank-backed "fiat currencies" (see note 1 ) around the world.

Riding the financial digitalization wave into a new frontier, and followed initially by 28 other companies of various business sectors, social media and networking giant Facebook announced in June 2019 its intention to launch a digital currency initially named "Libra", now called "Diem". The announcement came as a shockwave, though Facebook patents for this new currency had been filed in 2018 and registered in 2019 (cf. United States Patent and Trademark Office).

National governments and their central banks have traditionally enjoyed a kind of "monopoly" when it comes to deciding what counts as legal "currency". So long as paying taxes to the government and receiving paychecks in a national currency holds, that currency's legitimacy stands. Yet, if people could consume products or services using a new, widely available digital currency locally, in a way both simpler and cheaper than with the current economic system, then its impact on our daily lives might be far greater than many people have yet imagined. In other words, the launch of the Diem "token" could, if completed, have many and significant ramifications, and impact many spheres of daily activity in societies worldwide, including communications, business, and education, as well as the financial realm. 


\section{Facebook's Digital Currency Venture “Diem”: the new Frontier ... or a Galaxy far, far away? Jahja Rrustemi \& Nils S. Tuchschmid}

This paper focuses on Facebook's digital currency designs and plans to be built using "blockchain" distributed ledger technology (DLT). However, since digital currency cannot be disentangled from the broader concept of "money", we first briefly explore what money means. In section two, we discuss "local" currencies and the "decentralized" (see also, "distributed" or "P2P sharing") financial system that stems from these currencies. The next section presents Diem's network architecture and business model, relying on various documents, including Diem Association white papers, transcripts from U.S Congress hearings, and several other articles, in both "yellow" and academic literatures. The following section considers the business motivations behind Facebook's initial intention to launch a digital currency, its potential risks, and the limitations that led to a revised version, now called "Diem" (Libra Association, 2020). The final section presents concluding remarks and several open questions for future exploration, framed as an invitation to further discovery as this broad social experiment develops.

\section{Money and Currency}

What is money? At first sight, the answer appears obvious. A few years ago, people would have seized their wallet and taken out their national central bank's notes. Others would have searched deep in their pocket and extracted coins. But all would have agreed that, whether notes or coins, it was money! Nowadays, people might show their "plastic" debit cards or their credit cards or even their smart phones. Money has become digitalized. But is it still money? Not really. Of course, it helps to explain what money could or should be, but only partially. Following William Stanley Jevons, economists have argued that money should fulfill three economic functions: it has to be a medium of exchange, a unit of account and a store of value (Jevons 1875).

By "medium of exchange", we mean that it has to be easily exchangeable and accepted as such between two counterparties in a deal. The examples of people showing bank notes, coins, debit, or credit cards and even their smart phones, were just illustrations of this first function (see note 2). As far as the "unit of account" is concerned, this refers to a standard unit of monetary measurement that can express the market value of a good, service, asset, or any transaction. Expressing values using a common benchmark speeds up the decision-making process and eliminates the conversion risk when both the unit of account and the medium of exchange are the same. Finally, "store of value" relates to the possibility of deferring payment for a set time by preserving the value of an asset and exchanging it later for the same value. Of course, for such a function to be acceptable, what is defined as money needs stability through time, which is a challenging task as, among other threats, it might be subject to inflation and deflation risks or, more prosaically, devaluation risk. Stated otherwise at its most basic level, the "value of money" and its purchasing power may change over time.

"Money" can be compared with the "currency" of a nation-state. Currencies like the Swiss franc (CHF) or the US dollar (USD) are widely perceived as both a medium of exchange and unit of account. But one might question whether they still count as a legitimate store of value. Who nowadays will physically pocket CHFs or USDs for retirement? Yet, the distinction is rather subtle. Currencies should be viewed as a form of money that is available and that circulates within a specific economic zone, be it the euro in Europe or dollar in the United States of America. Of course, some currencies might not display all the necessary characteristics to be called "money", and the less they do, the less attractive they are to potential users, and the more people will look for alternative monetary solutions (Wray, 2012). One can find enough examples of countries where the domestic currency was simply disregarded by its population, which instead adopted something else more reliable during a turbulent period.

Nowadays governments serve to "back" the medium of exchange for their national citizens through "fiat currencies". Yet fiat currencies are no longer backed by anything tangible or concrete. A $\$ 20$ USD bill is just an IOU issued by the US central bank (the "Federal Reserve") whose "value" is based on what is written on the note. Somehow, governments and central banks must guarantee that the value of their money as a reflection of the strength and vibrancy of their national economy will not decline to the point of disappearing, and will remain roughly stable over time. Nor can a government succumb to "default" on its financial obligations in people's minds. From trusting our neighbors or family members in the past for financing, now people trust governments and central banks to take out their "money" or get it back. 


\section{Facebook's Digital Currency Venture “Diem”: the new Frontier ... or a Galaxy far, far away? Jahja Rrustemi \& Nils S. Tuchschmid}

This point is crucial in understanding how the Diem project differs from previous "digital currencies". Digital currencies based on blockchain and other distributed ledger technologies (DLTs) are usually called "cryptocurrencies" because they use cryptographic functions or hash functions for transactions. Bitcoin and its current competitors all suffer from what has been perceived by many as a major flaw: lack of backing and unstable currency behavior (Kristoufek, 2015; Hayes, 2017; Kasper, 2017). The high volatility that has characterized the cryptocurrencies market so far suggests greater risk, along with the possibility of difficulties in properly transferring digital wealth through time. One possible solution suggests that the backing of powerful global corporations could help guarantee the persistence and existence of a mainstream digital currency, enabling a service like what governments do with fiat currencies. Diem aims to offer such a solution.

\section{Local Currencies and Decentralized Finance}

Economies at the local level can use what are called "local currencies" to promote their regional products and services. These currencies share some common features both with Diem and cryptocurrencies in general. Local currencies have existed for decades, yet with the advent of blockchain technologies and the possibility of "tokenization" (making a token), along with exchange value that doesn't require issuing promissory notes, new radical change may soon be upon us.

Local currencies rose in popularity during the 1990s due to a demand for locally produced goods and services (Jayaraman and Oak, 2001). Local businesses began to aim at preserving the specific characteristic of a town or region more than transregional businesses, while protecting and fostering the creation of local wealth (Schuman, 1998). Local currencies have also been developed with the intention of bypassing the limitation of a single currency system that sometimes constrains communities from local economic development (Grover, 2006).

The principal beneficiaries of local currencies are for the most part the economically excluded (Williams, 1996). Unfortunately, the prevailing flaw found by the local currency studies lies in the relatively low circulation and adoption rates of local currencies. This diminishes the significance of the research results. The "general public" has not yet widely adopted these currencies for use in everyday transactions. The reasons for this can be traced back to the three main functions of money referred to above. To summarize, local currencies do help in improving communities in some cases, yet the effect is somehow limited or minimal due to their low public adoption rate.

If local currencies were to develop, it would undoubtedly be in the form of cryptocurrencies and tokens, even though the ideals involved with the advent of decentralized finance (DeFi) through Bitcoin and Ethereum are different from local currencies (that is, borderless versus local economy). Yet, the technology behind the cryptocurrencies and the solutions it can provide are also applicable to local currencies. Although it can be argued that local currencies address very specific local conditions not well served by a national government currency, both cryptocurrencies and alternative currencies strive to diverge from the common and imposed government currency by creating new channels of exchange. Blockchain DLTs look set to answer those needs.

It is also crucial to understand that the way of thinking behind cryptocurrencies is drastically different from what currently exists in transaction cost economics (TCEs), which includes the presence of intermediaries or third parties. First, TCEs is driven by supply and demand, which invites arbitrage opportunities. DeFi built using blockchain technologies instead is established based on distributed trust (Seidel, 2018). Following Botsman (2017), distributed trust "flows laterally between individuals" without prior trust required. This new type of digital trust comes, of course, with its own deficiencies, in the form of various frauds and scams. Due to limited or non-existent regulatory and executive governance, the financial system is vulnerable to the emergence of unregulated innovations, which people with malicious intent can use to their advantage. Promises of delivering services that will never be fulfilled in exchange for e-money have been a recurring major concern expressed by investors, which is an issue for both cryptocurrencies and DeFi.

So far most blockchain-based projects have not yet gained mainstream users, likely due to their complex technological framework. To combat this weakness, decentralized financial services are striving to become increasingly user-friendly. However, it remains to be seen when non-tech-savvy people will be able to easily 


\section{Facebook's Digital Currency Venture “Diem”: the new Frontier ... or a Galaxy far, far away? Jahja Rrustemi \& Nils S. Tuchschmid}

access and use DLTs. Additionally, and perhaps paradoxically, a crucial need remains for a clear and standardized regulatory framework for DeFi around the world.

Current regulatory environments for cryptocurrencies are still uncertain and unsettled globally (Chen \& Bellavitis, 2019). Laws and regulations regarding the finance industry and financial services change frequently nowadays, a fact that can prove costly for business and investment. The uncertainty and volatility cause many companies to adjust their business model, change locations, or eventually go bankrupt. Laws pertaining to financial innovations in the digital economy are so far extremely varied country-to-country, and certainty is lacking in regard to future government policies on this matter. While cryptocurrencies have so far been highly volatile, this particular issue can be solved by "stable coins", with values that are usually pegged to fiat currencies. Diem is to be introduced as a "stable coin" that is pegged to multiple fiat currencies.

\section{The First Venture: Facebook's Libra version 1.o}

Facebook has been trying to get into the online payment market through the WhatsApp pay application after seeing the success of their Chinese counterpart, WeChat. Roughly $90 \%$ of payments by Chinese living in big cities use either WeChat's mobile payment method or Alipay (Mansoor, 2020). Yet, the WhatsApp application did not take off as expected and the use of mobile payments in many "western countries" still lags behind China, and other Asian and African countries.

The online payment market remains massive economically, which suggests enormous profit opportunities for early actors on the playing field. Although the WhatsApp pay attempt did not meet with the expected success, Facebook came back in 2019 with Libra, now called Diem, a new project that shares similarities with the previous idea. At the same time, they made it clear that they do not intend to stop at the initial 28 members, which included Paypal, Uber, eBay, and Vodafone. They were instead planning to expand the Association to over hundred members in the upcoming years.

Following the 1st white paper published in 2019, the
Association's main objective was stated as providing access to financial services and cheap capital worldwide, with a particular focus on underdeveloped countries. Through their platform, they aimed to reduce the costs of money movement throughout the world and presented their digital currency as a public good that would create "immense economic opportunities" (Libra Association, 2019a). The 1st white paper appeared mainly altruistic and consumer-friendly. Meanwhile, the private global companies that compose the Association have clear economic interests for being in the project.

Initially Libra, now Diem, is being built on blockchain technology. As an electronic currency, it was inspired by how blockchain is now being used in other digital currencies to "decentralize" finance. The Diem Association plans to include additional features for their electronic currency according to their business model, which we address below. The DLT behind Diem is designed to allow for scalability, meaning that they expect multiple billions of potential users simply due to the global outreach of the companies backing the project.

Diem also needs to be secure and flexible, which is only made possible by solving the so-called "trilemma" of blockchain technology between scalability, security and decentralization presented by Vitalik Buterin. Like most available cryptocurrencies, Diem is to be rolled out as a "decentralized network". Many DLTs rely on a "permissionless" system to verify the transactions in the blockchain network. "Permissionless" (in contrast with "permissioned") means that network members can join freely with the only restrictions imposed on them being what they have agreed to in the Genesis Block by joining that particular blockchain network. Overall, DLTs allow for greater transparency in business and personal transactions, as well as rendering it almost impossible to "hack" data (Haber \& Stornetta, 1991, 1997; Bayer et al., 1993; Massias et al., 1999). The question is whether Diem can solve this trilemma, and if its users will be convinced of the safety and privacy of their everyday personal financial transaction data.

It remains a key challenge to achieve both scale and speed of transactions. Transactions with DLTs take longer to execute the more users are active in the network, which is why the speed of transactions is so important. In Diem's case, network users would have to validate and "reach consensus" for transactions of 


\section{Facebook's Digital Currency Venture “Diem”: the new Frontier ... or a Galaxy far, far away? Jahja Rrustemi \& Nils S. Tuchschmid}

potentially more than a billion customers, which could prove unfeasible when Diem eventually gets rolled out (Catalini \& Gans, 2016; Catalini et al., 2019).

To address this, validation authority is granted to a restrained and trustable group of people, who, in this case, are members of the Diem Association. This feature of the project distinguishes the Diem digital currency as operating within a "permissioned" DLTbased system, designed to make it easier to scale, and which likewise fits with the Diem Association's ambitions. This move serves to give the Diem Association more control over Diem tokens and meanwhile lessens the financial power of network users.

A basic diagram explaining the overall architecture of the Diem ecosystem is provided in Figure 1. It is important to note that the validators must be understood as an integral part of the Diem Blockchain, and to the overall ecosystem process.

Notably, Diem will not use "mining", but will create demand by exchange for fiat currencies. In the 1st white paper (Libra Association, 2019a), Facebook's digital currency was then to be pegged to a basket of low volatility assets, composed of bank deposits and shortterm government securities. This type of digital currency is commonly called a "stable coin", as it avoids the high volatility risk by pegging its value to an already existing fiat currency.

The Diem Association's members will purchase the lowvolatility assets that go into the Diem reserve and provide potential owners or users the virtual equivalent of Diem at the existing exchange rate. These assets are to be selected from "stable countries" and for the most part, denominated in US dollars, euros, British pounds,

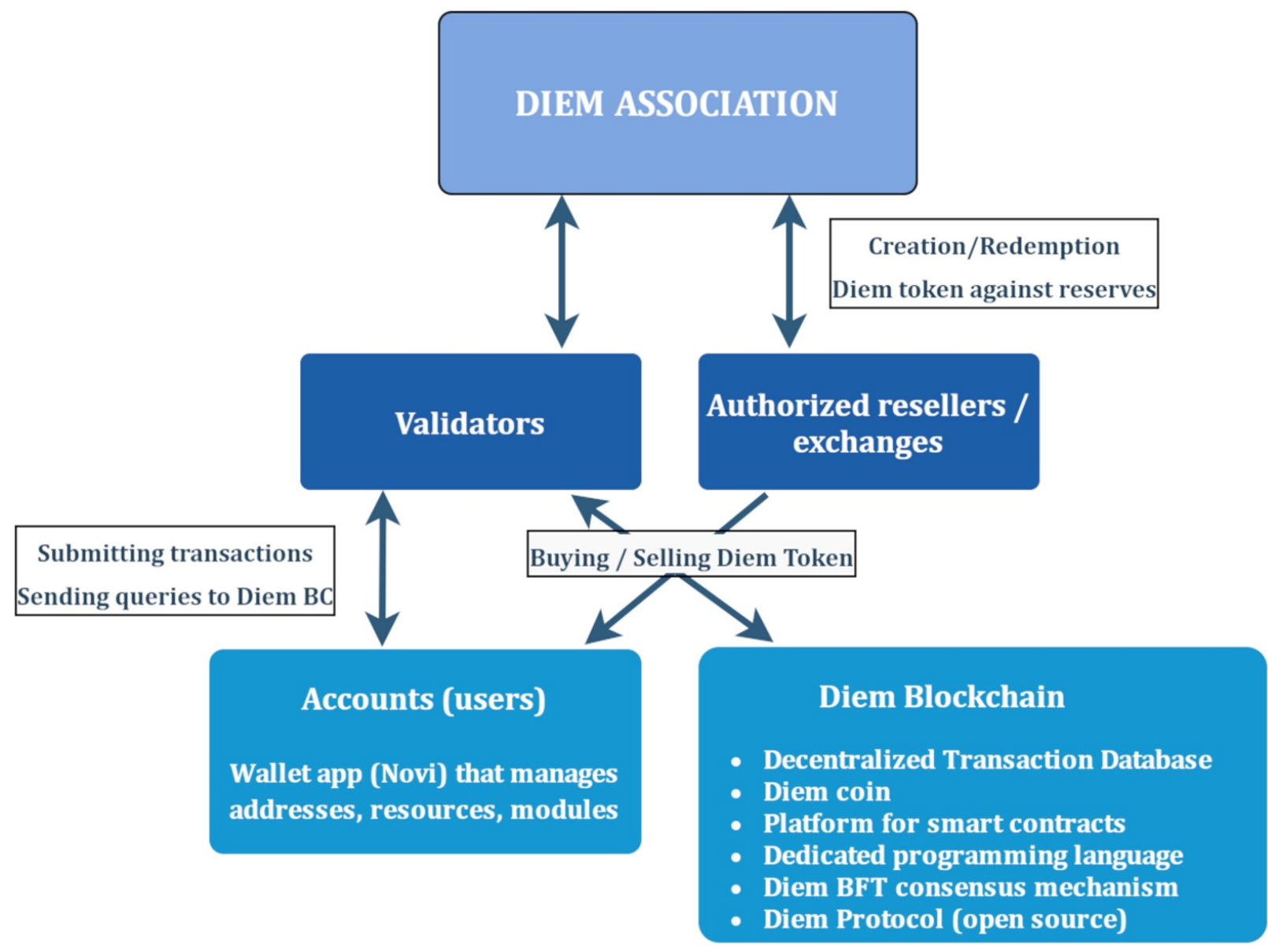

Figure 1. Diem ecosystem architecture

$\mathrm{BC}=$ blockchain, app $=$ application, $\mathrm{BFT}=$ Byzantine Fault Tolerant

Source: modified from Bruhl, 2020 


\section{Facebook's Digital Currency Venture “Diem”: the new Frontier ... or a Galaxy far, far away? Jahja Rrustemi \& Nils S. Tuchschmid}

or yen (Adrian \& Mancini-Griffoli, 2019). Facebook announced in September 2019 that the reserve would be composed of $50 \%$ USD, $18 \%$ EUR, $14 \%$ JPY, $11 \%$ GBP, and 7\% SGD. Hence, the Diem token's value would behave like an Exchange Traded Fund (ETF), by tracking a basket of short-term and high-quality securities, with strong exposure to USD. By operating this way, Facebook and the co-founders expect their digital currency's value to stay relatively stable, at least in a fashion similar to well-known fiat currencies.

Of course, "pegging" to fiat currencies is one thing, while trusting who manages and secures the digital currency is something else. In addition to Diem currency managed by the Association, comes a digital wallet, "Novi". It was initially called "Calibra", but the name was changed in May 2020. Thanks to Novi, the owners of Diem tokens will be able to save, send, and spend Diem. Novi wallets will connect with phones, tablets, computers, and are likely to integrate credit cards, following the statement of David Marcus, cocreator of Diem, during the U.S. Congress hearings (U.S. Senate. Committee on Banking, Housing and Urban Affairs, 2019). Novi is registered as a subsidiary of Facebook and is not under the direct influence of the Diem Association. David Marcus also declared that Novi would become completely autonomous from Facebook, and eventually a fully-fledged member of the Diem Association in the future, as an independent entity.

This topic is delicate for Facebook given Facebook's track record regarding private information, since the information stored in peoples' wallets is often most crucial and sensitive (Coombs, 2005; Cohen, 2013; Albright, 2018). The Novi wallet is designed to contain all recorded transactions of the individual Diem-user, including whatever private information they feed it. David Marcus made it clear during the hearings that they will not share account information with any third parties without consumers' consent, or use it to improve targeting ads on behalf of Facebook or any third parties. The Novi digital wallet will thus be essential to Diem's potential for success, as it is where the transactions and transfers of digital currency will take place.

\section{Opportunities and Challenges: The new version or Diem 2.0}

At first, Diem was said to be motivated by a desire to help emerging countries and the world. Thanks to cost reduction and easier accessibility, Diem would provide access to financial services and facilitate transactions between users worldwide (Libra Association, 2019a). Little was mentioned of other economic incentives behind undertaking this venture for Facebook and its business partners. Each member of the Association was required to invest at least 10 million US dollars to be part of the project. In return, each member would receive investment tokens granting them a share of the Diem reserve fund (Hochstein, 2019).

The costs of the project overall and how much Novi and Diem altogether have already cost Facebook are difficult to estimate. During the hearing in the U.S. Congress in July 2019, the Association representative at the time, David Marcus, continuously refused to mention the size of Facebook's investment. We can certainly speculate that the amount was quite substantial. A private company would require a defined business plan and clear return opportunities. Facebook is not a non-profit organization looking to better the world at their own expense, without expecting to recoup their investment. They were no clear-cut answers on how Facebook planned to turn a profit with the Diem token, if that was indeed its direct goal.

First, we imagine that costs or fees payable with Diem tokens would be attached to transactions to profit Facebook through Novi. Transaction fees currently exist in the competitive financial services market, even if many argue these fees are too high. Yet, Facebook promises that its fees will be lower than those charged by the banking industry (Libra Association, 2019a). Whether on Facebook or in banks, one must comply with national financial rules and regulations. Diem must go through anti-money laundering and terrorist financing procedures for all transactions to avoid liability. Diem Association members will also have to handle the exact same issues that financial actors have to deal with when operating worldwide payments, which represent the main bulk of costs. In short, one way or another it must be made sure that the money pouring into Novi wallets is not fraudulent or being used for illegal and nefarious purposes.

None of the identity and security procedures can be skipped. Blockchain brings no additional value in this regard, since the procedure is time-consuming and costly. Also, Facebook and its partners argue they will be able to provide financial services to people who are 


\section{Facebook's Digital Currency Venture “Diem”: the new Frontier ... or a Galaxy far, far away? Jahja Rrustemi \& Nils S. Tuchschmid}

currently left out and at a lower cost, especially in underdeveloped countries. First, among the vast number of people currently not using financial services, only those with access to mobile technology or internet could see Diem as a solution. According to GSMA Intelligence (2020), there are around 5.2 billion smart phone users worldwide, that is $67 \%$ of the world population, and 4.57 billion internet users, or $59 \%$ of the world population, according to the International Telecom Union (2019). Yet, following a report from the World Bank in 2018, around 1.1 billion of the "unbanked" adults have at least a mobile phone and nearly half of them have internet access, suggesting that Diem could be of use for them. Secondly, Facebook will have to set up some sort of system where people in those countries can exchange their national fiat currency from and to Diem. Be it through local banks, shops, phone companies, or any other third party, the exchange intermediaries create higher fees, which might be similar to current rates offered by the competition.

However, one can speculate that transaction fees will not be the main source of revenue, especially when the Diem Association's reserves constitute an important asset that can be used to generate profit if managed correctly. It is crucial to understand this topic, while many questions regarding it are in our view still left unanswered. The Diem Association will be the one managing the financial assets of the reserve acquired by selling (exchanging) Diem to (with) clients. The white paper 1.0 specified that any interests gained will "be used to cover the costs of the system, ensure low transaction fees, pay dividends to investors who provided capital to jumpstart the ecosystem" (Diem, 2019). It seems evident to us that Diem's idea of cutting costs is ambitious at best and that they will likely either operate without profits or will have to increase fees at some point.

To the above question regarding how Diem intends to initially finance the low transaction fees, it is likely that they expect to finance it thanks to investments from the reserve fund, which will be composed mainly of short-term government bonds. Unfortunately for Facebook and the Diem Association, the current economic environment is plagued by very low interest rates, and the future is uncertain in this respect. If Diem's economic ecosystem depends on returns from their reserve fund, then the Diem project is much riskier financially than initially thought.
Diem tokens should then be looked at as shares in a managed fund that are also used as a medium of exchange. What would then happen in case the fund does not provide enough returns? Would the managers extend the duration of the financial instruments, pick different currencies, or invest in securities with lower creditworthiness? In other words, the reserve fund might have to revert to the initial promise of keeping a fixed proportion of low volatility currencies. The Diem Association addressed this in its 2.0 White Paper, which reads that the "activities of Libra Networks are governed and constrained by a Reserve Management Policy that can only be changed by a Member supermajority, subject to regulatory approval" (Libra Association, 2020). The goal here is to be licensed and regulated by a national authority, in this case the Swiss financial regulator FINMA.

Still, the argument above is valid only if the Diem Association has no other sources of profit available, should they be unable to cover operating costs. During the US congress hearing, David Marcus very briefly mentioned that in the upcoming years they intended to make loans available to users, which they expected would also become a source of profit. In other words, in addition to creating a digital currency as a means of payment, Facebook intends to offer typical banking services soon as well. Facebook has insisted that they will maintain a one-to-one ratio in their reserve requirements, which is surprising considering the fact that to provide loans, they would need to make use of assets sitting in their reserve, and thus bypass that ratio. Mr. Marcus was further questioned on this specific matter, saying the Diem Association would simply trust the word of private companies that they would not change the reserve. This is not saying much and his answers remained evasive. Legislators suspected a change would occur with the reserve requirements at some point, as the profitability seems too good to look past. Banks work this same way, except that the traditional central bank's role in the new economic ecosystem will be replaced by the Diem Association, which would have to put up additional funding from its founding members in case things turn for the worse. If lowering the reserve requirements is not an option, the Diem Association will have to turn to external parties or future members that could provide the necessary financial services the project requires. In case Facebook decided to provide loans through Novi, the Diem Association would truly compete with the banking sector and potentially national central banks, 


\section{Facebook's Digital Currency Venture “Diem”: the new Frontier ... or a Galaxy far, far away? Jahja Rrustemi \& Nils S. Tuchschmid}

in both providing currencies and exchanging money for clients.

If Diem's launch and subsequent network growth manages to create a strong enough ecosystem, where the currency becomes a vital part of a country's economy, then it could heavily undermine the power of that country's central bank to conduct its policies. Many governments were thus understandably quite reluctant initially about DeFi through digital currencies. Even if Diem agreed not to adjust the reserve requirements or change the reserve's investment policy for five years, ten years or even twenty years, what would happen afterwards? A mere change of board members or a majority vote would enable transforming the Diem Association's policies. Simple promises that reserve changes will not happen were definitely not enough, considering the magnitude of the matter at hand, that is, a potential conglomerate with billions of customers that can possibly print money and implement their own monetary policies.

Aside from using the Diem Association reserves as a tool to raise profits, revenue is expected to also come from the ecosystem Diem creates. By the sheer increase of traffic in their platform, Facebook expects to increase revenue from ads. If Diem and Novi become essential to peoples' lives as much as Facebook has for some people, it is safe to say that revenue will increase if advertisements are also part of the project.

To summarize, the Diem venture has raised many concerns and faces strong headwinds for its nearfuture launch. Only a few months after getting started, the project had to deal with a set of significant blows: the departure of five members of the Diem Association and negative comments from government representatives and politicians. In an interview published in December 2019, then Swiss President, Ueli Maurer, for example, stated that "The Libra project has failed in its current form and needs reworking to be approved" (Hughes, 2019). Worse, the French government declared that they intended to block Diem from developing on European soil, although it is doubtful on what legal ground such a restriction would be implementable. All in all, the latter were not reassuring signs concerning the future of Diem in its initial form.

To answer concerns raised by politicians, regulators, and central bankers, the Diem Association announced in their April 2020 Diem 2.0 white paper that they plan also to offer single currency stable coins, in addition to the standard Diem token composed of multiple currencies. This means that Diem USD, Diem EUR, Diem GBP, for example, will each be available to customers, backed by securities denominated in these specific currencies, so as not to interfere with the monetary sovereignty of those countries. Stated otherwise, the new Diem is more becoming a global value platform where multiple single currencies can be "plugged" in (see Sandner, 2020).

To this set of "single-currency" stable coins or "programmable currencies", Diem will be backed by a basket of currencies (see figure 2 below). Diem will thus act as a kind of "substitution currency" only for places where stable currencies are lacking. The final goal for Diem tokens is to "integrate smoothly with local monetary and macroprudential policies and complement existing currencies by enabling new functionality, drastically reducing costs and fostering financial inclusion" (Libra Association, 2020). Regarding initial concerns about the possibility of the Diem Association offering loans, they responded in the 2020 white paper that they will not be providing loans from their reserves (Libra Association, 2020). Instead, they will be potentially turning to third parties to offer these services through the Diem network, thus reducing risks the Diem association could pose to central banks.

The rebranding of the project from Libra to Diem in December 2020 and the reinforcement of the management team by bringing in new senior executives seems to aim at showing organizational independence and increasing the likelihood of regulatory approvals. Indeed, Diem was designed not only for Facebook alone. One may thus wonder what the other Diem Association founding members expect? The private companies that joined hands in this project came from different backgrounds. Hence, they complemented each other in a way that would allow future consumers to gain access to a range of products and services using Diem tokens. The products and services offered by the Diem founding members aimed to fulfill most of a consumer's needs.

Altogether, the Diem Association initially included companies in industries, ranging from telecommunications to online shopping and traveling. 


\section{Facebook's Digital Currency Venture “Diem”: the new Frontier ... or a Galaxy far, far away? Jahja Rrustemi \& Nils S. Tuchschmid}

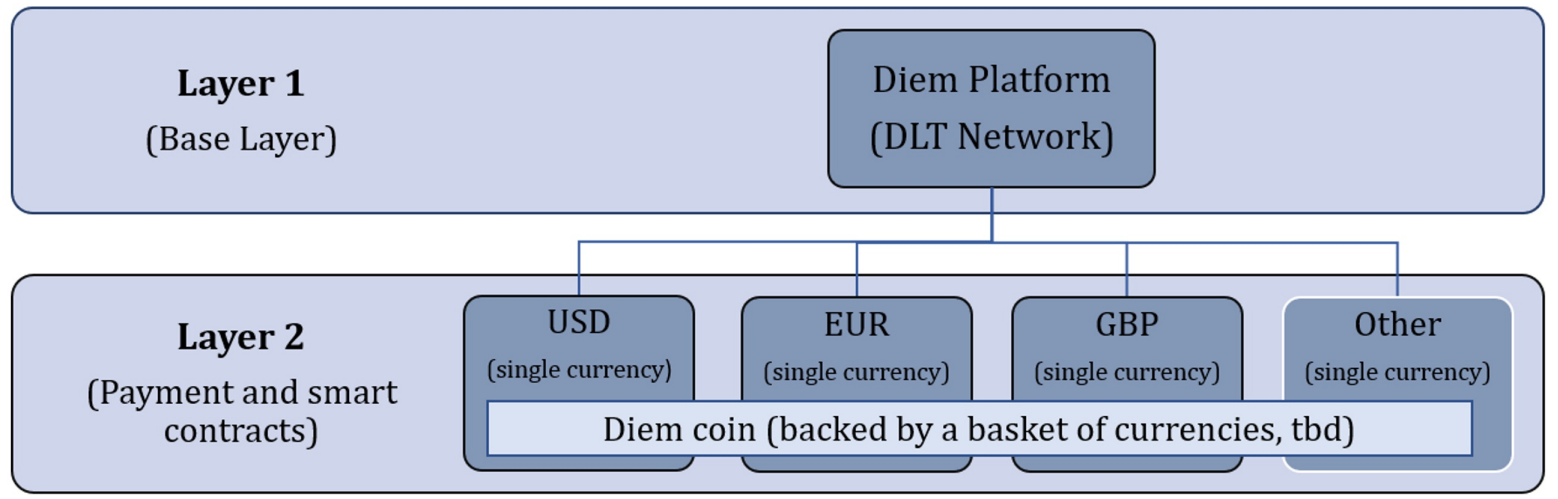

Figure 2. The Diem 2.0 architecture

Tbd $=$ to be determined

At the time of founding, the Diem Association was composed of 28 members. Currently, there are 26 members; 8 have left and 6 new members have joined. Most of the big financial companies departed, like Ebay, Mastercard, Paypal and Visa. Among the newer entrants, one finds a payment system company, an ecommerce company, a cryptocurrency brokerage firm, and a few venture capitalists.

If a broad range of consumers can access most of their necessities from the Diem network and become accustomed to using Diem, the "network effect" will also increase volume for member companies in the Diem Association. They would be able to segment a large piece of the market for themselves, assuming the overall network can convince people to adopt Diem. In simple words, future customers would be enticed to use Diem exclusively and, by consequence, to buy products solely from Diem members (Reitman, 2019). Clearly, legislators have reason to worry about the possibility for the Diem Association proposing preferential rates and prices to Diem token users. This raises concerns of unfair competition that drives away opposition. Worse, barriers to entry would increase for new participants. Competitors may be forced to either join the Diem Association or suffer from market loss. Executive repercussions would be quite important, and we could expect a similar grouping of competitors to counteract the Diem Association, perhaps with an alternative DLT-based digital currency.

\section{Future Challenges, Questions and Final Remarks}

What we can see at play in Facebook's Diem venture goes much deeper than simply offering financial services to people around the world who currently lack basic access to them. The arguments raised in this paper lead finally to the ethical elephant in the room: Facebook's past actions and what they entail in this instance. Diem - and Facebook in particular - keep reiterating that they are aware of the former scandal (see Facebook-Cambridge Analytica data scandal) concerning the monetization of personal account information. They insist they will make their best effort to ensure that such a breach will not happen again.

Can Facebook and the Diem Foundation be believed and trusted? Is what they have said and guaranteed about security and privacy sufficient? Or should they be held to account and opposed by legislators and regulators? Just as with Central Bank and other currency-creating matters, actions speak louder than words in business execution and network building. Several issues with Diem remain problematic that we believe have not yet been satisfactorily tackled in the white paper and additional Diem documentation.

The rebranding and reorganizing of the Association was one step in the right direction, but more is needed. According to German finance minister Olaf Scholz regarding Facebook's digital currency plans, "a wolf in sheep's clothing is still a wolf" (Schalal and Kraemer, 2020). Facebook's reports and updates suggest humanitarian motivation behind the creation of Diem: billions of people are left behind and, thanks to the Diem network, a solution may be available. Yet, believing that Facebook, together with its megacorporate global partners, are motivated mainly by altruistic reasons, we believe would be simply naïve. 


\section{Facebook's Digital Currency Venture “Diem”: the new Frontier ... or a Galaxy far, far away? Jahja Rrustemi \& Nils S. Tuchschmid}

While we have noted that the Diem project faces many obstacles, we also foresee profitability from using Diem tokens that can be investigated and developed. The biggest earning potential in the Diem project definitely comes from the information that its Diem token and Novi wallet users will provide while using the Facebook-Diem financial system, with its market reach through advertising, online "stores", merchandising, and service offerings. The potential to target not only advertisements, but also provide financial services and products to boost consumer demand through Diem transactions makes an obvious source of revenue for a consortium-network with "user currency" that can be organized with an aim to capturing profits.

Although Facebook promises its users that security breaches of their personal data will not happen again, it may be a promise they truly mean, but simply cannot keep. Information is and has always been a key component of Facebook's recipe for high tech success, just as it will continue to be with the addition of Diem tokens. A kind of new craze with what is called "big data" can now be seen with Diem as a quest for a far, far away galaxy still to be conquered. The Diem Association will be sitting on a gigantic goldmine of information ready for the taking and harvesting for massive profits. Who will blame them that they took advantage of the moment it was ripe to do so?

\section{Acknowledgments}

We would like to thank our colleagues, Jean-Marie Ayer and Bruno Pasquier, for their useful comments and remarks. We are particularly grateful to Gregory Sandstrom managing editor of the TIM Review and to an anonymous reviewer for their numerous and valuable suggestions that have allowed us to improve our paper. All remaining errors are ours.

\section{Notes}

1) "Fiat currency" is to be understood as a "legal tender" backed by a government, but which has no other use value without secure legal protection. Legal tender refers to the fact that the currency is a medium of payment recognized by a national, territorial, or other jurisdictional legal system.

2) For many, money arose simply to avoid the limitations of barter that are assumed to have been prevalent in early human societies. A barter system is known to be greatly restrictive, with both parties having to agree on a value for the different goods and subsequently finding a common ground to match the offers of both sides (Goodhart, 1998). Some, however, have disagreed with this view, as it might sound a bit too "simplistic" and not confirmed by historical observations (Graeber 2011).

\section{References}

Albright, J. 2018. The Graph API: Key Points in the Facebook and Cambridge Analytica Debacle. Accessed online at:

https://medium.com/tow-center/the-graph-apikey-points-in-the- facebook-andcambridgeanalytica-debacle-b69fe692d747

Bayer, D., Haber, S. \& Stornetta, W.S. 1993. Improving the Efficiency and Reliability of Digital TimeStamping. Sequences II: Methods in Communication, Security and Computer Science: 329-334. https://doi.org/10.1007/978-1-4613-9323-8_24

Berentsen, A. \& Schär, F. 2018. A Short Introduction to the World of Cryptocurrencies. Federal Reserve Bank of St. Louis Review, First Quarter, 100(1): 1-16. https://doi.org/10.20955/r.2018.1-16

Botsman, R. 2017. Who can you trust? How technology brought us together and why it might drive us apart. Public Affairs, New York.

Brühl, V. 2020. Libra: a differentiated view on Facebook's virtual currency project. Intereconomics, 55: 54-61. https://doi.org/10.1007/s10272-020-0869-1

Brunner, K. 1968. The Role of Money and Monetary Policy. Federal Reserve Bank of St. Louis Monthly Review, 50(7): 8-24.

Catalini, C. \& Gans, J.S. 2016. Some Simple Economics of the Blockchain. Paper no. w22952. National Bureau of Economic Research. http://dx.doi.org/10.2139/ssrn.2874598

Catalini, C., Kominers, S.D. \& Jagadeesan, R. 2019. Market Design for a Blockchain-Based Financial System. Working paper no. 3396834. Social Science Research Network. http://dx.doi.org/10.2139/ssrn.3396834

Cohen, J.E. 2013. What is Privacy for? Harvard Law Review, 126.

Coombs, K.A. 2005. Protecting User Privacy in the Age of Digital Libraries. Computers in Libraries, 25(6): 1620. 


\section{Facebook's Digital Currency Venture “Diem”: the new Frontier ... or a Galaxy far, far away? Jahja Rrustemi \& Nils S. Tuchschmid}

Chen, Y., \& Bellavitis, C. 2019. Decentralized Finance: Blockchain Technology and the Quest for an Open Financial System. Stevens Institute of Technology School of Business Research Paper.

http://dx.doi.org/10.2139/ssrn.3418557

Dalton, G. 1967. Primitive Money. Tribal and Peasant Economies. Austin, TX and London, UK: University of Texas Press: 254-81.

https://doi.org/10.1525/aa.1968.70.4.02a00140

DeVries, P.D. 2016. An Analysis of Cryptocurrency, Bitcoin, and the Future. International Journal of Business Management and Commerce. Vol. 1 (2), September.

Farrington, A. 2019. Money, Banking, Bitcoin, Libra. The Startup. Available at: https://medium.com/swlh/money-banking-bitcoinlibra-191183d5e825.

Friedman, M. 1968. The Role of Monetary Policy. American Economic Review, LVIII (1): 1-17.

Goodhart, C. 1998. The Two Concepts of Money: Implications for the Analysis of Optimal Currency Areas. European Journal of Political Economy, 14 (3): 407-32.

Graeber, D. 2011. Debt: the first 5,000 years. Brooklyn, N.Y.: Melville House. https://doi.org/10.1111/ehr.12005_16

Grover, D. 2006. Would local currencies make a good local economic development policy tool? The case of Ithaca Hours. Environment and Planning $C$ : Government and Policy, 24: 719-737. https://doi.org/10.1068/clp

GSMA Intelligence 2019. The Mobile Economy. GSMA Intelligence Report.

Haber, S. \& Stornetta, W.S. 1991. How to Time-Stamp a Digital Document. Journal of Cryptology, Vol 3(2): 99111 .

https://doi.org/10.1007/BF00196791

Haber, S. \& Stornetta, W.S. 1997. Secure Names for BitStrings. Proceedings of the 4th ACM Conference on Computer and Communications Security, April: 28-35.

https://doi.org/10.1145/266420.266430

Hayes, A.S. 2017. Cryptocurrency Value Formation: An Empirical Study Leading to a Cost of Production Model for Valuing Bitcoin. Telematics and Informatics, 34: 1308-132.

http://dx.doi.org/10.2139/ssrn.2648366.

Hochstein, M. 2019. There's a Second Token: A Breakdown of Facebook's Crypto Economy. Available at:

https://www.coindesk.com/theres-a-second-tokena-breakdown-of-facebooks-blockchain-economy.

Hughes, B. 2019. Facebook's Libra has failed in current form: Swiss president. Reuters.
Innes, A.M. 1913. What is money? Banking Law Journal, May: 377-408.

Jayaraman, R. and Oak, M. 2001. Local currency as a development strategy. Working paper.

Jevons, W. Stanley. 1875. Money and the Mechanism of Exchange. D. Appleton.

Kasper, J. 2017. Evolution of Bitcoin: Volatility Comparisons with Least Developed Countries' Currencies. Journal of Internet Banking and Commerce (JIBC), vol. 22, no. 3. http://dx.doi.org/10.2139/ssrn.3052207.

Kristoufek, L. 2015. What Are the Main Drivers of the Bitcoin Price? Evidence from Wavelet Coherence Analysis. PLOS ONE, 10(4). https://doi.org/10.1371/journal.pone.0123923

Libra Association. 2019a. An Introduction to Libra. White paper.

Libra Association. 2019. The Libra Reserve. White paper.

Libra Association. 2020. Libra White Paper 2.0. White paper.

Light J. and Carville O. 2019. Libra Loses a Quarter of its Members as Booking Holdings Exits. Bloomberg.

Lee, R. 1996. Moral money? LETS and the social construction of local economic geographies in Southeast England. Environment and Planning A, 28: 1377-1394.

https://doi.org/10.1068/a281377

Mansoor, I. 2020. WeChat Revenue and Usage Statistics. Available https://www.businessofapps.com/data/wechatstatistics/

Marsh, A. 2019. Facebook Token Runs into Instant Political Opposition in Europe. Bloomberg.

Massias, H., Avila, X.S. \& Quisquater, J.-J. 1999. Design of a Secure Timestamping Service with Minimal Trust Requirements. 20th Symposium on Information Theory in the Benelux, May 1999.

Moore, G. 2014. Crossing the chasm: Marketing and selling disruptive products to mainstream customers. Harper Business, 3rd edition, New York.

Merkle, R.C. 1987. A Digital Signature Based on a Conventional Encryption Function. Advances in Cryptology - CRYPTO '87, 16-20: 369-378. https://doi.org/10.1007/3-540-48184-2_32

Nakamoto, S. 2008. Bitcoin: A Peer-to-Peer Electronic Cash System. Unpublished paper, available at https://bitcoin.org/bitcoin.pdf.

Peacock, Mark S. 2006. The Moral Economy of Parallel Currencies. American Journal of Economics and Sociology, 65 (5): 1059-1083.

https:/ /doi.org/10.1111/j.1536-7150.2006.00491.x 


\section{Facebook's Digital Currency Venture “Diem”: the new Frontier ... or a Galaxy far, far away? Jahja Rrustemi \& Nils S. Tuchschmid}

Sandner, Phillip. 2020. Understanding Libra 2.0: A compliant global platform for the digital programmable EUR, USD, GBP \& Co. Own personal website.

https://medium.com/@philippsandner/libra-2-0-acompliant-global-platform-for-the-digitalprogrammable-eur-usd-gbp-co-67e1b8a2c0cb

Schuman, M. 1998. Going Local: Creating Self-reliant Communities in a Global Age. The Free Press, New York.

Schalal, A. and Kraemer C. 2020. G7 finance officials back need to regulate digital currencies: Treasury. Reuters. Available at:

https://www.reuters.com/article/g7-digital/g7finance-officials-back-need-to-regulate-digitalcurrencies-treasury-idUSKBN28H1Y6

Seidel, M. 2018. Questioning centralized organizations in a time of distributed trust. Journal of Management Inquiry, 27 (1): 40-44.

https://doi.org/10.1177/1056492617734942

Smith C. and Kaminska I. 2019. What exactly is Facebook's Libra Reserve? Financial Times.

Studer, T. 1998. WIR and the Swiss National Economy. WIR Bank report.

Taskinsoy, J. 2019. Facebook's Libra: Why Does US Government Fear Price Stable Cryptocurrency? Working paper.

https://doi.org/10.2139/ssrn.3482441

Tooke, T. 1959. An Inquiry into the Currency Principle: The Connection of the Currency with Prices and the Expediency of a Separation of Issue from Banking. The London School of Economics and Political Science.

U.S. Senate. Committee on Banking, Housing and Urban Affairs. 2019. Examining Facebook's Proposed Cryptocurrency and Its Impact on Consumers, Investors, and the American Financial System. Testimony of David Marcus.

Williams, C. 1996. Local purchasing schemes and rural development: an evaluation of local exchange trading systems (LETS). Journal of Rural Studies, 12: 231-244. https://doi.org/10.1016/0743-0167(96)00025-3

Wood, G. 2016. Ethereum: A Secure Decentralized Generalized Transaction Ledger. http://gavwood.com/paper.pdf

World Bank Group 2017. Measuring Financial Inclusion and the Fintech Revolution. The Global Findex Database.

Wray, R. 2011. Introduction to an Alternative History of Money. Levy Economics Institute. Working paper. https://doi.org/10.2139/ssrn.2050427

\section{About the Authors}

Jahja Rrustemi is a scientific collaborator at the Haute Ecole de Gestion Fribourg (HEG-FR), University of Applied Sciences and Arts Western Switzerland (HES-SO). He holds a Master of Science in Wealth Management at the University of Geneva. The main focus of his research relates to Portfolio Allocation Methods, Risk Minimization, Forwardlooking Risk Measures as well as Cryptocurrencies and the Tokenization of the economy.

Nils S. Tuchschmid is professor of Finance and head of the Finance Institute at the Haute Ecole de Gestion Fribourg (HEG-FR), University of Applied Sciences and Arts Western Switzerland (HES-SO). Before joining HEG-FR, Nils was a Partner, Head of Tactical Trading Strategies and Chairman of the Investment Committee at Tages Group. Previously, he was the Co-Head of the Alternative Funds Advisory team at UBS and Head of Multi-Manager Portfolios at CreditSuisse. He also worked as Strategist and Head of quantitative research and alternative investments at Banque Cantonale Vaudoise. Nils was Professor of Banking and Finance at HEG Geneva and Professor of Finance at HEC Lausanne University. He holds a Ph.D. in Economics from the University of Geneva.

Citation: Rrustemi, J., \& Tuchschmid, N.S. 2020. Facebook's Digital Currency Venture "Diem": the new Frontier ... or a Galaxy far, far away? Technology Innovation Management Review, 10(12): 19-30. http://doi.org/10.22215/timreview/1407

Keywords: Bitcoin, blockchain, crypto assets, cryptocurrencies, Diem, Diem Association, digital currency, distributed ledger technology, Facebook, fiat currencies, financial industry, financial inclusion, Libra, local currencies, tokenization 